\title{
Chapter 1 \\ Introduction: Japanese Theories and Overview of the Chapters in This Book
}

\author{
Masami Isoda and Raimundo Olfos
}

This introductory chapter explains the origin of this book and provides overviews of every chapter in Parts I and II of the book. Part I of the book is aimed at explaining what multiplication and lesson study are in relation to the Japanese approach. It provides an overview of Japanese theories on mathematics education for developing students who learn mathematics by and for themselves and it provides necessary ideas to understand the Japanese approach and lesson study. Part II consists of contributions from leading researchers in Ibero-America. Through their contributions, this book provides various perspectives based on different theories of mathematics education which provide the opportunity to reconsider the teaching of multiplication and theories.

\subsection{Origin of This Book}

This book originated from collaborative research done by the editors since 2008 . When Olfos studied Japanese lesson study with Isoda at the University of Tsukuba, Olfos was amazed by how Japanese students mathematically communicate the curriculum content and subject matter by themselves in their classroom under the problem-solving approach. They reorganize new mathematical knowledge by themselves based on what they have already learned under the learning trajectory in their curriculum sequence. Before he arrived in Japan, his image of problem solving was to recall and use learned content to solve new content. However, the Japanese problem-solving approach is done under the task sequence planned by the teachers

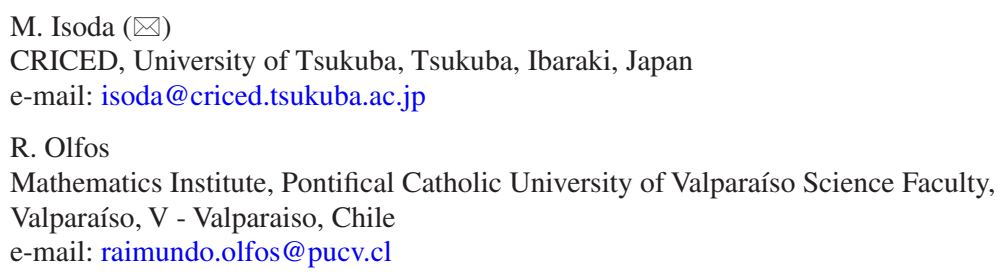


and textbooks for students to reorganize mathematical knowledge by using what they have already learned. At the same time, he recognized that there were big differences in the curricular content, textbooks, tasks, and teaching content in schools. In Chile, most children attempt (but do not memorize at all) the multiplication table in the earlier grades. However, the Japanese teach the multiplication table for enabling students to learn how to extend the multiplication table by themselves. Through discussion about the Japanese approach from the perspective of Chile, the editors recognized that the teaching of multiplication is an exemplar for sharing Japanese practical theories in mathematics education to establish coherent and consistent alignment of the curriculum, teaching practice, and assessment.

To this end, the editors published lesson study books in Spanish (La Enseñanza de la Multiplicación: El Estudio de Clases y las Demandas curriculares [in English: Teaching of Multiplication: Lesson Study for Curricular Demands] (Isoda and Olfos, 2009a) and El Enfoque de Resolución de Problemas: en la Enseñanza de la Matemática: a Partir del Estudio de Clases [in English: Problem Solving Approach: Mathematics Teaching on Lesson Study] (Isoda and Olfos, 2009b) to explain the Japanese approach. For comparison of the first book with the Ibero-Americans' proposals, Enseñanza de la Multiplicación: Desde el Estudio de Clases Japonés a las Propuestas iberoamericanas [in English: Teaching Multiplication: Japanese Lesson Study and Ibero-American Contributions] was published in Isoda and Olfos, 2011 with leading researchers from Ibero-America.

Part I of this English-language book is a revision of Part I and Annex of the 2011 Spanish-language book on multiplication under the current international curriculum reform movement. It aims to develop twenty-first-century skills and competencies including the human character, values, attitudes, and way of thinking (Isoda and Katagiri, 2012; Mangao, Ahmad, and Isoda, 2017). Part II of this book comprises excerpts from Part II of the 2011 Spanish-language book. This is a new book on multiplication in relation to Japanese lesson study.

This chapter briefly explains the Japanese theories that are used by teachers for designing and implementing lessons, and gives an overview of the subsequent chapters to provides the perspectives of this book in teaching multiplication.

The Organisation for Economic Co-operation and Development (OECD) (2005) has defined competencies for curriculum reform for students to be able to succeed in this changing and refunctioning society by using the words "successful life" and "well functioning society". The United Nations (2015) seeks the establishment of high-quality education on SDG4. To address these issues, curriculum reforms are under way. This book provides ideas for high-quality education and theoretical overviews for better teaching of multiplication in a competency-based curriculum based on the experiences in Japan and Ibero-America.

\subsection{Overview of Japanese Theories for Designing Lessons}

Through Japan's remarkable economic growth up until the early 1990s and its highest achievements in several international surveys in mathematics (such as the International Association for the Evaluation of Educational Achievement (IEA) 
Trends in International Mathematics and Science Study (TIMSS), and the Program for International Student Assessment (PISA)) since 1964, Japanese education and its system have become internationally influential. Especially in the 1980s, the system of the Japanese national curriculum standards influenced England and the USA. ${ }^{1}$ The Japanese ways of teaching began to spread to developing countries through JICA in the 1990s. ${ }^{2}$ Japanese teaching approaches and lesson study have been learned internationally since around 2000 in relation to Stigler and Hiebert (1999) and NCMS (2000). Especially, NCMS praised Japanese lesson study from the aspect of teachers' collaboration for long term development. Then, collaboration of teachers modeled by lesson study became one of research trends. Robutti et al. (2016) mentioned that it is not always successful because Japanese lesson study is a kind of cultural practice and there are missing informations. Indeed, Japanese lesson study has a long tradition dating back to 1873 (Isoda, 2007, 2020; Makinae, 2010, 2016; Baba, Ueda, Ninomiya, and Hino, 2018). The first guidebook for lesson study was written by Wakabayashi and Shirai (1883) and was aimed at improvement of teaching and learning by adoption of the Pestalozzi method and Zen/ Confucian-style dialectical questioning. The book explained the principles of teaching under the Pestalozzi method, dialectical questioning and tasks for inquiry, objective-based lesson planning, and ways of critical discussion after observation of the class (such as preferred teaching materials and methods, and observed activities

\footnotetext{
${ }^{1}$ In Japan, schools that follow the national curriculum standards are recognized as schools that are supported by the government. The national standards are the bases for textbook authorization and national assessments. Authorized textbooks follow the standards, $90 \%$ of curriculum standards content on compulsory education and $80 \%$ on senior secondary education. After authorization, they can be called textbooks and freely selected by the district. Every school is supposed to manage its own curriculum under these conditions. Most schools' curricula follow the textbooks' recommended curriculum; however, lessons are planned beyond these limitations, depending on the teachers. It looks like a top-down system; however, it includes lesson study, which involves a bottom-up system. For example, well-recognized approaches and teaching materials will be embedded into the new edition of textbooks. For revision of the curriculum, a laboratory school usually proposes new approaches and teaching materials. In Japan, there are no private educational consultants who provide schools with their own/original curriculum, lesson plans, worksheets, tools, and methods of teaching. However, lesson study produces learning communities for innovation and sharing of ideas on curriculum development and implementation in every classroom. In Japan, results of lesson studies will be embedded into curriculum and textbooks. In countries which do not have the consistent curriculum alignment such as the countries do not have national standards, or countries that teachers don't have custom to follow the standards even they have, teachers usually use worksheets copied from various different resources. In this type of worksheet culture, it is not easy to establish a coherent system under the curriculum alignment (see such as Squires, 2012) like the system in Japan. Indeed, on the worksheet culture, the teaching time distribution to the contents are not the same and if teachers use different worksheets, they find it difficult to estimate and utilize what students have learned in the past. Then, the teachers have to try to make sense of the teaching content at every class. In Japan, teachers are able to engage in sense making (McCallum, 2018) for future learning to be able students to learn by and for themselves. See Chap. 5.

${ }^{2}$ Singapore had the opportunity to study the Japanese system and the Japanese approach at the end of the 1970s (in a 5-year project with Japanese overseer development assistance). Since 1982, the Ministry of Education, Japan, has provided an 18-month program at teacher education universities. Each year, more than 150 teachers from Southeast Asia and other region study the Japanese approach, which includes learning mathematics education, in the program.
} 
of the teacher and students), with exemplary protocols for every subject in the curriculum. This was the beginning of Japanese general theories for designing lessons, which are not known internationally, as we discuss in the preface to this book.

Japanese theories for mathematics education as for the school subject specific theories (Herbst \& Chazan, 2016) are based on the didactics ${ }^{3}$ of lesson study involving math educators, which can be seen from four perspectives (Isoda, 2020). The first perspective is the theories that clarify the aims and objectives in every class. The national curriculum standards constitute an authorized document that explains the objectives. To clarify the objective of teaching, math educators have prepared related theories such as mathematical thinking. The second perspective is the terminologies used to distinguish conceptual differences in teaching content. The third perspective is the theory used to establish the curriculum sequence and task sequence. The fourth perspective is the theory used to manage lessons. These theories have been prepared by math educators through lesson study. ${ }^{4}$

\footnotetext{
${ }^{3}$ To date, a limited number of research articles on lesson study have focused on Japanese cases, such as Miyakawa and Winsløw (2013), analyzing lesson study by using French didactics. In Part I of this book, Japanese didactics mean design theories of practice to develop students' competency to learn mathematics by and for themselves under the curriculum. This means that Japanese didactics is oriented toward realizing the aims of mathematics education. For teachers, it is not necessary to mean the theoretical frameworks for social scientific analysis on empirical studies even it can be used for (see such as Huang and Shimizu, 2016).

${ }^{4}$ In the community of math educators, when we say "theory," most math educators might imagine theoretical frameworks, such as French didactics, which are used for observation, analysis, and description of the research object. It is necessary to contribute to the research community for educators. On the other hand, the Japanese mathematics education theories which used by teachers and educators orient the design science and are necessary to develop and explain better teaching practices for students as for reproducible science (Isoda, 2015a). Thus, the bases are the aims and objectives, followed by the terminology to distinguish the teaching content, and then the sequence of teaching and the method of teaching. For example, French Didactics does not include aims and objectives in its theories although it includes anthropological approaches in mathematics education and design-based research (see the Encyclopedia of Mathematics Education (Lerman, 2014)). In French didactics, the aims and objectives are analyzed under the terminology/framework on didactics: see such as Rasmussen \& Isoda (2018) in the case of mathematical thinking. Conversely, when Japanese teachers refer to the aims and objectives in curriculum documents as terminology for their lesson plan, they continuously use the same terminology. For example, developing students who learn mathematics by and for themselves is written into the curriculum document (see Ministry of Education, 1998). The teachers try to prepare teaching sequences, materials, and methods to develop students toward this shared aim which functions likely an axiom. On this meaning, Japanese Theories are the aims and objectives based, normative, theories for educators and teachers. Lesson study has been functioning for their theorizations. Japanese theories are referred and functioning in various lesson study community though the national level publication for designing, observing and explaining the classes and students' developments. Japanese math educators also use social scientific theories however it is not the major scope in Part I for illustrating the theories on lesson study.
} 


\subsubsection{Mathematical Thinking and Activity: Aims and Objectives}

The Japanese aims of education have been described as three pillars: human character formation (such as values and attitudes), general thinking skills (such as mathematical thinking and ideas), and specific knowledge and skills (such as mathematical knowledge and skills). If we change the terminology, the principle aims are common not only for Japan but also for other countries such as the Southeast Asian countries (Mangao et al., 2017).

The first two pillars are usually explained as higher-order thinking skills in many countries and also as the learning content for learning how to learn. It is usual for teachers to write or share these objectives through the lesson plan. According to the Japanese principle of the national curriculum, these aims are symbolized by a single concept: "Developing students who learn mathematics by and for themselves" (Shimizu, 1984). In Japanese mathematics education, this has been recognized in relation to mathematical activities as for reorganization of living and life (Ministry of Education, 1947). The activity has been re-explained as mathematical thinking and attitude (Ministry of Education, 1956) by Japanese math educators, who have tried to explain it further. Shigeo Katagiri (see Katagiri, Sakurai, and Takahasi, 1969 and Katagiri, Sakurai, Takahasi, and Oshima, 1971), who was a curriculum specialist in primary school mathematics in the Ministry of Education, established the framework for mathematical thinking with teachers (Isoda and Katagiri, 2012, 2016). ${ }^{5}$

In Japanese lesson study, Table 1.1 is used for clarifying the curriculum, task sequence, teaching materials, ${ }^{6}$ and methods of teaching. It is not a list of hints such as the strategies for solving problems adapted from Pólya (1945) but is used for precise descriptions of objectives for every teaching material in the lesson and for considering its processes as for preparation of future learning. It is also used to write the lesson plan for clarifying the objectives of teaching, which explains why it is necessary to practice like that. Table 1.1 is used for writing these objectives more concretely and clearly with teaching materials. ${ }^{7}$ This framework also provides the general study theme of lesson study beyond every objective of the teaching content. ${ }^{8}$

Katagiri also developed the list for questioning in the classroom in relation to teaching phases for Table 1.1.

\footnotetext{
${ }^{5}$ The Japanese teachers' manner of preparation will be illustrated in Chap. 7.

${ }^{6}$ Teaching materials mean the content or the task of mathematics embedded objectives in the curriculum. In Japanese mathematics education, development of mathematical thinking is a part of the aims of the national curriculum standards.

${ }^{7}$ Katagiri's framework is historically known. There are several projects for further revision of his framework on the context of 21st century skills (Mangao et al., 2017) in ASEAN region and computational thinking for 4th Industrial revolution in APEC region.

${ }^{8}$ The recursive process of lesson study can be continued according to the study theme even though the teaching content changes every time.
} 
Table 1.1 Types of mathematical thinking according to Katagiri (published in English in 2012)

I. Mathematical attitudes: Mindset

1. Attempting to grasp one's own problems, objectives, or entities clearly by oneself

(a) Attempting to have questions

(b) Attempting to be aware problematic

(c) Attempting to find further problems from situation

2. Attempting to take logical-reasonable actions (reasonableness)

(a) Attempting to take actions that match the objectives

(b) Attempting to establish a perspective

(c) Attempting to think based on the data that can be used, previously learned items, and assumptions

3. Attempting to represent matters clearly and simply: Clarity

(a) Attempting to record and communicate problems and results clearly and simply

(b) Attempting to sort and organize objects when representing them

4. Attempting to seek better ways and ideas

(a) Attempting to raise thinking from the objects to operations

(b) Attempting to evaluate thinking both objectively and subjectively, and to refine thinking

(c) Attempting to economize thought and effort

II. Mathematical thinking related to mathematical methods: Mathematical Ways of Thinking

1. Inductive thinking

2. Analogical thinking

3. Deductive thinking

4. Integrative thinking (including extension)

5. Developmental thinking

6. Abstract thinking (thinking that abstracts, concretizes, and idealizes, and thinking that clarifies conditions)

7. Thinking that simplifies

8. Thinking that generalizes

9. Thinking that specializes

10. Thinking that symbolizes

11. Thinking that represents by numbers, quantities, figures and diagrams

III. Mathematical thinking related to mathematical contents: Mathematical Ideas

1. Clarifying sets of objects for consideration and objects excluded from sets, and clarifying conditions for inclusion (the idea of sets)

2. Focusing on constituent elements (units) and their sizes and relationships (the idea of units)

3. Attempting to think based on the fundamental principles of expressions and the permanence of form (the idea of expression)

4. Clarifying and extending the meaning of things and operations, and attempting to think based on this (the idea of operation)

5. Attempting to formalize operation methods (the idea of algorithms)

6. Attempting to grasp the big picture of objects and operations, and using the result of this understanding (the idea of approximation)

7. Focusing on basic rules and properties (the idea of fundamental properties)

8. Attempting to focus on what is determined by one's decisions, finding rules of relationships between variables, and using relationship (functional thinking)

9. Attempting to express propositions and relationships as formulas, and to read their meaning (the idea of formulas) 


\subsubsection{Terminology and Sequences: Extension and Integration}

The terminology distinguish conceptual differences and its development in curriculum content. It includes the technical terms to distinguish conjectural differences such as different meaning of multiplication and the representations such as Tape Diagram and Proportional Number Lines for overcoming such differences. It is necessary to explain the process of reorganization of mathematical concepts in the curriculum sequence. The Japanese established most of it between 1900 and the 1960s (see the special issues of the Journal of Mathematics Education published by the Japan Society of Mathematical Education in 2010). ${ }^{9}$ The related terminology for multiplication will be explained in Chaps. 3 and 4 in Part I of this book in relation to the historical development of school mathematics and current research perspectives. Japanese teachers need to learn the terminology of school mathematics for developing students who learn mathematics by and for themselves because the school curriculum sequence cannot exist as a system deduced from the set and axioms such as pure mathematics (see Freudenthal (1973)).

The sequence in the Japanese curriculum standards has been explained by the principle of "extension and integration" since 1968, which is oriented toward enhancing mathematical activities and developing mathematical thinking. It corresponds to the principle of reinvention by Freudenthal (1973) who proposed mathematization as the reorganization of mathematical experience (see Isoda, 2018).

Under this principle, the school mathematics curriculum can be seen as a set of partially ordered local mathematics theories, like a net that is consistent within every local theory like a knot; however, on extending and integrating local theories, the net has some inconsistencies in connecting the local theories, like entangled strings among knots. Japanese textbooks are written for students to be able to extend and integrate mathematics by and for themselves (see Chaps. 4 and 7). ${ }^{10}$ The questions mentioned in item 1(a) of the "I. Mathematical attitudes" section of Table 1.1 (by Katagiri) are written for producing such mathematical problematic situations, not only for problems posed in real-world situations such as mathematical modeling.

Such inconsistencies through the extension and integration of local theories in relation to multiplication are explained by adaptation of the conceptual and procedural knowledge to meaning and procedure in Fig. 1.1 (Isoda, 1992, 1996, 2009). ${ }^{11}$

\footnotetext{
${ }^{9}$ In relation to multiplication in this book, Izsák and Beckmann (2019) discussed the same idea, such as the definition of multiplication by measurements and proportional number lines; however, the Japanese established it in 1960s. See Chapter 3.

${ }^{10}$ It means that Japanese textbook has the task sequence for Zone of Proximal Development (ZPD; Vygotski, 1978) by using what they already learned and preparing for future. Murata (2008) illustrated the function of tape diagram as a model for ZPD.

${ }^{11}$ In 1992, Isoda proposed the design theory of the task sequence with adaptation of conceptual and procedural knowledge from Hiebert (1986) and published eight lesson study books in Japanese as the product of lesson studies; more than 200 lessons, ranging from the first grade to the tenth grade, were produced using this theory. Later, similar theories were also proposed by Hiroshi Tanaka and Kei Ohono, teachers of the Elementary School at the University of Tsukuba.
} 


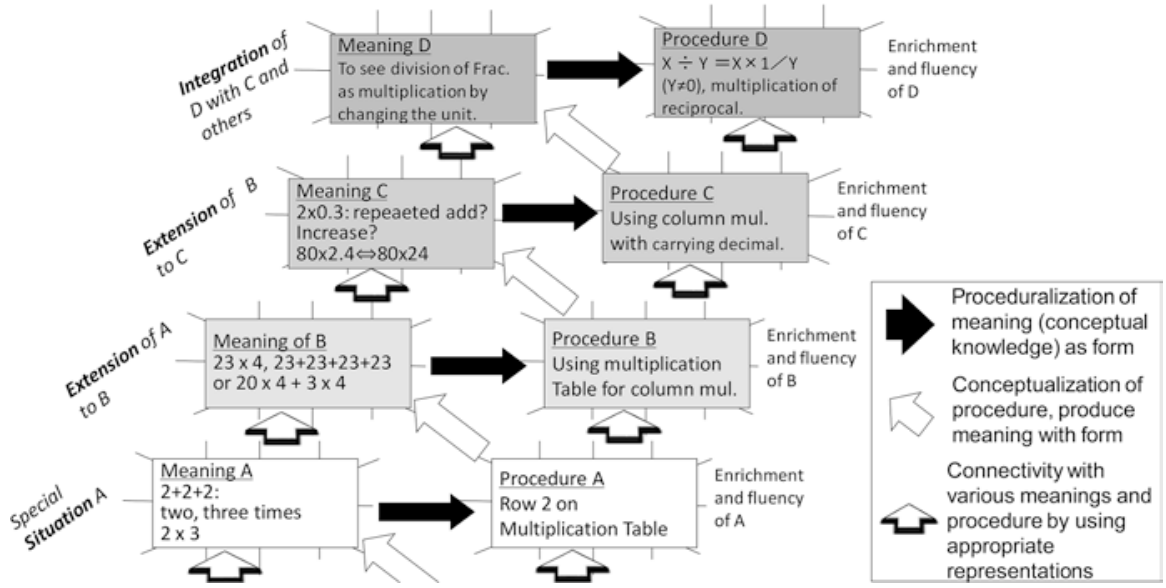

Fig. 1.1 Simplified extension and integration process of multiplication (mul.) in the task sequence detailed in the textbooks, which is explained by conceptual and procedural knowledge (Isoda, 2009)

How do you explain the sequence of conceptual development in Fig. 1.1? Conceptual and procedural knowledge are used to explain the development of personal knowledge; however, in Fig. 1.1, we use them to design and explain task sequences in the curriculum. In the curriculum sequence, as in textbooks, these are not discussed at the same time. Conceptual knowledge is usually taught for meaning; however, it needs to use some known form of procedure. After introducing the meaning of multiplication as a binary operation (expression), the multiplication table is proceduralized from repeated addition; otherwise, students cannot distinguish it from addition as a new operation. In the process of extension and integration, inconsistencies usually appear. For example, for doing multidigit multiplication, students need to see the multidigit numbers under the base ten system for applying the multiplication table instead of just repeated addition. For the extension of multiplication to multidigit numbers with column methods, multiplication as repeated addition should be integrated with the base ten system by using the rule of distribution. If we extend multiplication from whole numbers to decimals, the product of multiplication becomes small in case. It cannot be explained well as repeated addition. In the Japanese textbooks and Japanese teachers' lesson design (as shown in later chapters) these processes are discussed more precisely in relation to the task sequence.

In the terminology of the "learning trajectory", progressive relationship of conceptual and procedural knowledge in Fig. 1.1 are not easily seen as two different 
sides of the same coin. ${ }^{12}$ On the task sequence in Japanese textbooks, as in the curriculum, it might be clearly distinguished. One of the reasons is that it is possible for students to learn the procedure without knowing when the procedure should be used. This may seem like a strange statement; however, the textbook provides the opportunity to exercise a set of similar tasks for getting fluency of the procedure. "If $A$, then $B$ " is the format of the procedure. In the exercise in the chapter, students do only exercise $B$ for solving given tasks. The condition, a part of $A$, is not necessary to consider in the exercise for practicing the same tasks.

Before the extension of multiplication to decimal numbers, the product of multiplication only increases: "If it is multiplication of whole numbers, then the products become large." However, until extension of whole number to decimals, whole numbers are numbers, so it looks correct to say, "If it is multiplication of numbers, then the products become large." This is possible learning content for students through the exercise in the textbook chapter. The necessity for all students to think about conditions in relation to $A$ will be provided when students learn multiplication of decimals. Actually, when students learn whole numbers, they do not know about decimals. Students are able to learn $A$ when they encounter multiplication of decimal numbers. ${ }^{13}$ Another reason is related to the shortage of the capacity of working memory. If we limit working memory, procedures are very convenient and firster for doing multiplication. Students do not need to consider the meaning of $A$, because the numbers given in the exercise are not decimals. They have already established a convenient procedure that can be used without considering the original meaning of $A$. After students attain fluency in the procedure, many students do not feel the necessity to go back to and interpret the original meaning of the situations. Many of them lose/compartmentalize it because they do not need to think about the condition of $A$ as long as they are applying it to learned situations. The opportunity for extension and integration is a chance to reorganize their mathematics by comparing what they already knew and their developed mathematical ideas. At the moment of extension and integration on the task sequence, students are able to establish the significant meaning.

\footnotetext{
${ }^{12}$ This metaphor was popularized by Sfard (1991). She illustrated by using the history of mathematics. In the case of Japan, it can be illustrated by using the textbooks under the curriculum standards. Isoda (1992) established his theory on his lesson study groups in Japan such as province at Sapporo, Ibaraki, Tokyo, Toyama, Fukuoka and Okinawa by using the theories of Hiebert (1986). Simon (1995) characterized 'hypothetical learning trajectory' on teachers' instructional design. Clements \& Sarama (2004) characterized 'learning trajectory' by a learning goal, developmental progressions of thinking and learning, and a sequence of instructional tasks. Japanese textbooks under the national curriculum standards are well established the task sequence which enable to develop mathematical thinking by using already learned and for preparing the future learning. Japanese textbooks are products of the huge experience and challenges of lesson study in whole Japan. On the consequence of their recursive revisions, all six textbook-companies' series under the national curriculum standards become similar. Japanese teachers are able to produce their learning trajectry based on the experience of lesson study as the design and reproducible science. Thus, it is not just a personal hypotheths.

${ }^{13}$ Tall (2013) explained this with his terminology "met before."
} 


\subsubsection{Problem-Solving Approach: Not Only a Teaching Method}

If you have a chance to observe a lesson in a Japanese elementary school, the Japanese problem-solving approach looks the same as an open-ended approach, ${ }^{14}$ which involves posing an unknown task, solving the task in various ways, comparing solutions with the whole class, and summarize. However, the Japanese problem-solving approach is prepared in the following ideas: aims and objectives for developing students who learn mathematics by and for themselves, terminologies to explain the learning content, the curriculum and task sequence which connect past, current and future learning, and the teaching materials. On the other hand, an open-ended approach is characterized by an open-ended task. Consequently, the teaching materials used in the Japanese problemsolving approach are not the same as open-ended approach for an independent task, topic, or content of mathematics because problem-solving approach is explained under the aims, objectives, task sequences and preparation of future learning.

In the Japanese problem-solving approach, ${ }^{15}$ the task given by the teacher to the class means that the teacher prepare the teaching material which embeds the objectives in the task sequence. Thus, when you read a Japanese textbooks without considering the context and objective embed in the task sequence, it is just reading content but not regarding it as teaching materials. On the Japanese problem-solving approach, students reinvent the objective of the class from the given task as problematic. It was planned by the teacher to encourage them to think mathematically. The contradictions in the planned task sequence are necessary in this context. Given this limitation, the following exemplar on how the Japanese use the board in the lesson is meaningful (Fig. 1.2).

In this book, the Japanese approach means all those consequences and does not imply just a method of teaching like the scaffolding used to construct a building. Every component is explained by the theories and used for designing the classroom.

These theories are the models that will be illustrated in Part I of this book. Please note that there are several other theories in Japan, and many of them have been proposed through critical discussions such as curriculum sequences. For example, the extension and integration principle provides task sequences that go against the general-to-specific principle proposed by the mathematicians' group of Hiraku Toyama since the 1950s with the name of the water supply method (a metaphor from general-to-specific, see Kobayasi, 1989). Against the general-to-specific approach, several counter theories were proposed to support extension and integra-

\footnotetext{
${ }^{14}$ In Japan, open-ended tasks appeared before and in the middle of World War II. This idea was proposed by Shimada in 1977 (published in English by Becker and Shimada (1997) and theoretically elaborated by Nohda $(1983,2000))$. In Japan, the problem-solving approach was named arround 1950 in the context of progressivism and then was renamed in the 1980s in the context of the Agenda for Action (NCTM, 1980). The teaching style itself could be seen in the format of the lesson plan before World War II.

${ }^{15}$ Tall (2013) explained it as "lesson study" because "problem solving" in English merely implies solving an unknown task or exercise.
} 


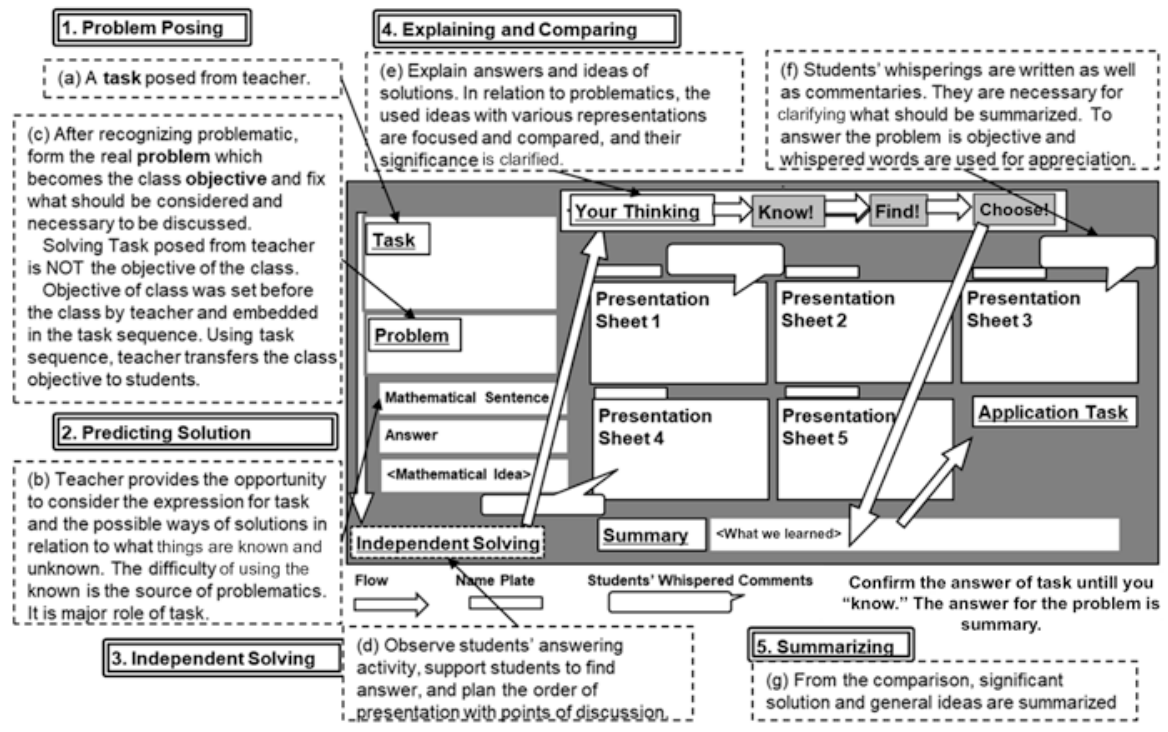

Fig. 1.2 A lesson plan format by using the board in the problem-solving approach (Isoda, 2012)

tion, some called it mathematization or discovery, such as Ito's theory as a representative of 1961, 1962a, 1962b, 1962c, 1963a, 1963b, 1963c. Ito's theory to mediate ideas by models (representations) such as proportional number lines (Ito, 1968) was named "discovery methods" by Ito (in English, 1971). ${ }^{16}$ Toshio Odaka established schema theories $(1975,1979,1980)$ for a problem-solving approach (see School Mathematics Study Society at the Junior Secondary School of the Tokyo University of Education, 1969, 1970, 1971, 1972), inspired by the idea of Piaget for supporting the extension and integration principle from the tradition of mathematization in the 1943 national textbook. Odaka produced a counter theory to explain an appropriate curriculum and task sequence_-called the "exemplar approach"—against Toyama's general-to specific sequence and schema theory, and completed as his task sequence for problem solving approach (Odaka \& Okamoto, 1982)

\footnotetext{
${ }^{16}$ Ito established the Japanese theory of proportional number lines which also included the idea of the definition of multiplication by measurements and tape diagram, wrote textbooks, and published seven guidebooks for teachers. He proposed proportional number lines for overcoming the inconsistency between local theories in the process of extension and integration. His theory is an integration of existed theories as discovery methods. Currently, his discovery method by consistent using of diagram can be seen from the perspective of the representation theory for Zone of Proximal Development. Isoda learned the theory for proportional number line from Prof. Tatsuro Miwa at the University of Tsukuba in 1981 on his undergraduate class for the elementary school mathematics curriculum. The same idea can be seen in Izak and Beckman (2019). Ito proposed his theory against the definition by attributes in relation to the Toyama group (Kobayasi, 1989). The theory by Toyama group will be discussed in Chap. 3 .
} 
Tadao Kaneko, written by Sakai and Hasegawa (1989), also theorized a task sequence for specific-to-general and an exercise sequence for general-to-special (1987). Shigeru Shimada proposed the open-ended approach (1977; originally he began the study in the 1960s) based on his experience of the 1943 textbook under the mathematization principle, and Nobuhiko Nohda retheorized it as the open approach (1983). There were discussions about embedding open-ended tasks into textbooks in the 1980s. ${ }^{17}$ Their theory for open-ended tasks itself did not indicate the manner to establish the task sequence for conceptual development in curriculum, directly. Odaka's, Kaneko's, and Isoda's theories were proposed for the task sequence as for conceptual development on the curriculum under the principle.

\subsubsection{Change Approaches for Developing Students and Teachers}

Lesson study around the world is usually focusing on the open class such as that shown in Fig. 1.3. The most necessary activity for any teacher is the preparation of the lesson for setting the teaching materials which embed the objectives into the teaching content and process. In the process of planning the board writing (Fig. 1.3), teachers usually prepare various types of questioning for inquiry (known in Japanese as hatsumon).

There are three types of questioning by teachers and students from the viewpoints of the objectives: ${ }^{18}$ The first type is questions of mathematical interest such as the task given by the teacher (see box (a) in Fig. 1.2), and the problematic posed by the students (see box (c) in Fig. 1.2). The second type is questions on teaching and learning in the teaching phases (see boxes 1-5 in Fig. 1.2) to provide the opportunity for reflections on what the students have learned that day in the summary (see box 5 in Fig. 1.2). The third type is meta-questions, which enable students to provide questions (like teachers) by and for themselves internally, such as "What do you want to do next?"19

In the lesson study process, after the open class, in the postclass discussions, the quality of the classroom communication by students is usually a subject for critique. If the students did the third type of questions by themselves well, a major point of discussion after the class observation is usually how the teacher developed the students to think mathematically. The teacher usually explains his or her everyday efforts to prepare future learning with deep understanding of the teaching materials and sequences. To develop values, attitudes, and mathematical thinking, the second and third types of questions are necessary; however, the questions do not exist without the

\footnotetext{
${ }^{17}$ Their discussion about questioning in mathematics was not so far to the questioning the world (Chevallard, 2015), and the Study and Research Path (SRP) (Winsløw, Matheron, and Mercier, 2013), which is related to the open approach by Nohda (2000), is a good framework to illustrate the open inquiry process. However, the Japanese problem-solving approach is more oriented to the task sequence to achieve the objectives and aims of the curriculum.

${ }^{18}$ See the introductory chapter and pp. 127-128 in Isoda and Katagiri (2012).

${ }^{19}$ See the Introductory Chapter of Isoda and Katagiri (2012). Hideyo Emori (2013) also mentioned similar ideas in classroom communication.
} 


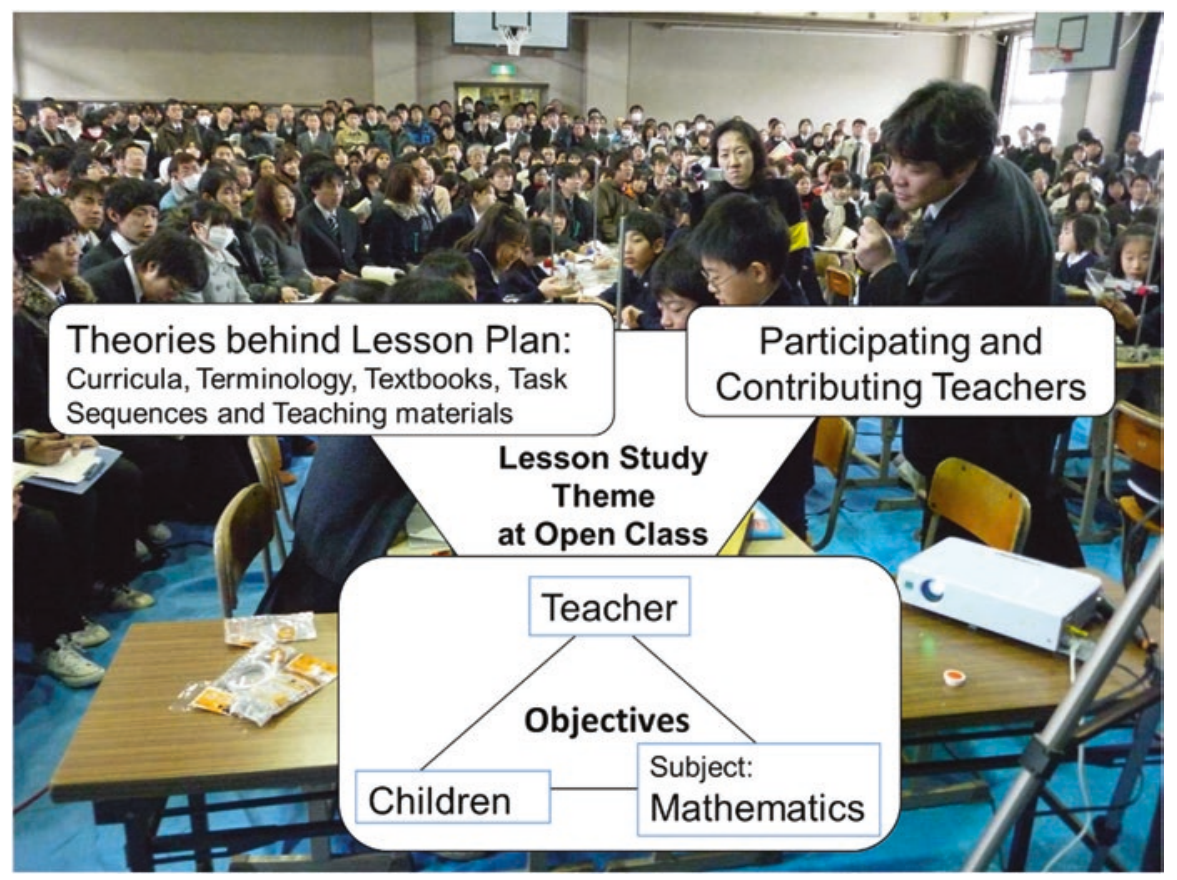

Fig. 1.3 What shall we discuss and observe?

first type in mathematics class. Thus, all questions are not just for the method of teaching but are also associated with the teaching materials and task sequences. In this context, Japanese teachers try to develop teaching materials by clearly embedding the objectives into the content under the task sequence in their preparation of the class.

In the postclass discussion, student-centered approaches are usually recommended instead of teacher-centered approach, and sometimes the qualities of the subject, mathematics, are not focused on, even they observed students activity. In Japanese lesson study, teachers discuss the achievement of the objectives and the study theme in the lesson plan. The study theme, innovative proposals, and challenges, are explained by the teacher with the teaching materials, as well as the specific objective of the task under the sequence. Then, alternative possibilities in relation to the objective and study theme are discussed based on their observation of class. All of them are related to the teaching materials.

Depending on the objective, a teacher-centered approach may be preferable. For developing students to learn mathematics by and for themselves, the view of mathematics is not the same. It depends on the teaching material and the objective prepared by the teacher (see Fig. 1.4). Exercise is necessary for acquisition of fluency in knowledge and skills. If the objectives are focused just on acquisition, mathematics can be seen as a set of knowledge and skills. An open approach is possible if teachers change the ordinal task to be open ended. Here, mathematics has various answers, which are the subject of communications. By using open-ended tasks, 
Which examples do you prefer for the area of trapezoid?

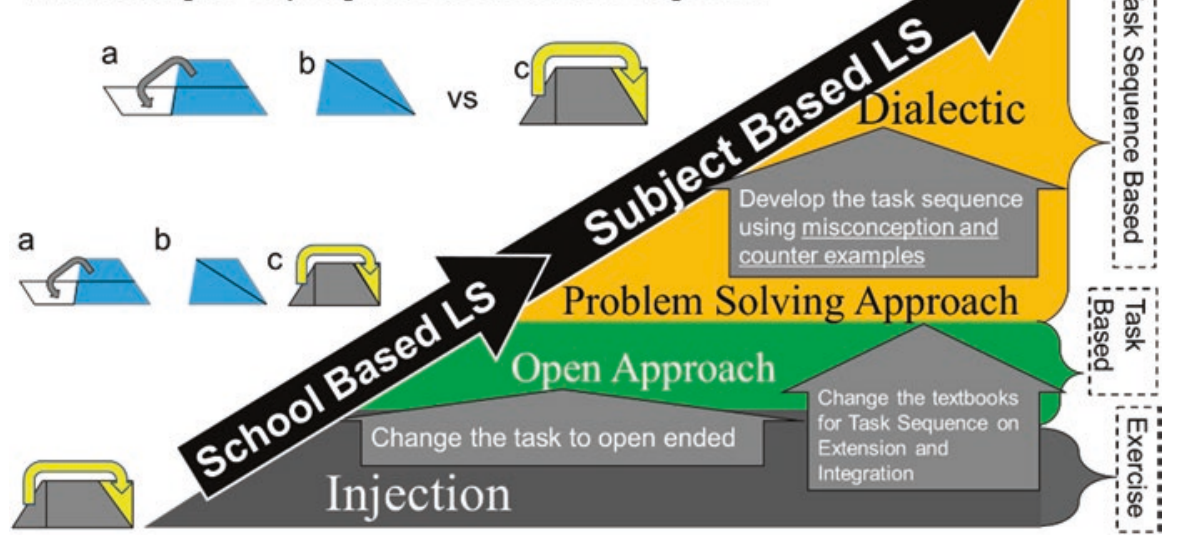

Fig. 1.4 Various approaches for developing students on lesson study (LS)

students and teachers usually learn ways of learning/teaching in the classroom. If they can use a textbook that has an appropriate task sequence for students based on the extension and integration principle, students can learn mathematics as a subject of extension and integration. This is a way to change the approach from being teacher centered to student centered. It is usually one of target of school based lesson study which is done within every school.

If teachers can use student's misconceptions and counter examples, they are able to develop students who have minds for proof and refutation (Lakatos, 1976; Isoda, 2015b). ${ }^{20}$ However, dialectical discussions are not easy for students who are only learning mathematics through teachers' explanations and exercises. It is also difficult to plan dialectical discussions for most teachers, because they cannot imagine the process for proof and refutation in school mathematics. Thus, in school-based lesson study, primary schools usually choose a problem-solving approach as the goal of training teachers by using appropriate textbooks.

On the subject of mathematics-based lesson study, many teachers are already able to teach with an open and problem-solving approach in their classes, and then they try to establish their own original task sequences for their classroom students. Such challenges are usually seen in the mathematics lesson study group at the Elementary School attached to the University of Tsukuba and the Sapporo mathematics lesson study group. These teachers produce the textbooks and try to make it possible to practice in school-based lesson study. The examples of lessons shown in Part I of this book were produced by these teachers.

In school-based lesson study at elementary schools, it is not easy for every teacher to focus on mathematics as dialectics. In this sense, it is oriented toward a student-centered approach. Subject-based lesson study is done by math major teach-

\footnotetext{
${ }^{20}$ Lakatos was Hegelian in the context of Karl Popper; proof and refutation are a kind of dialectic. It is the bases for to develop critical thinkers in mathematics class. However, dialectic discussion in the classroom is not popular in the world even though it can be seen from first grade of elemental school.
} 
ers and is oriented toward a subject-centered approach. In Part I of this book, we focus on Japanese multiplication, which is shared by the Japanese mathematics lesson study groups and textbooks as a result of long-term development of a subjectcentered approach as well as a student-centered approach.

\subsection{Overview of Chapters in Part I: The Japanese Approach}

Part I of this book illustrates the Japanese approach to multiplication through comparison of other perspectives. The theories used to design Japanese lesson study will be also illustrated.

In Chap. 2, the national curricula of seven countries are compared for confirmation of their differences and diversities, and for posing questions regarding teaching of multiplication, which will be answered in Chaps. 3, 4, 5, 6, and 7 in relation to the Japanese approach. The questions posed in Chap. 2 are related to the meanings and definition of multiplication, the necessity of appropriate selection of meanings for teaching other content such as division and extension of numbers (illustrated in Chap. 4), ways of teaching the meaning of multiplication and the multiplication table in relation to memorization, ways of teaching algorithms (the column method) for multiplication of multidigit numbers, and appropriate grades for introducing multiplication.

In Chap. 3, in relation to the question of defining the meaning of multiplication, the definition of multiplication in pure mathematics is confirmed first. Then, situations explaining the meaning of multiplication and the various types and uses of properties are discussed. Further, the Japanese definition of multiplication by measurement, which extends the group of groups, is introduced. This definition of multiplication becomes a keyword to explain the Japanese approach. The difference in language structure that produces inconsistency in teaching multiplication in IndoEuropean languages is also explained. The learning of children using their language and ways of thinking through the subject of elementary school mathematics are also presented. The terminologies explained in Chaps. 3 and 4 provide the bases of multiplication and lesson study in other chapters.

Chapter 4, in relation to the question of teaching of other content, illustrates the Japanese consistent curriculum sequence and terminologies to adapt the idea of multiplication to division and extend it to decimals and fractions. It further illustrates how the Japanese curriculum and textbooks are planned to develop and reorganize students' mathematical ideas for multiplication up to proportionality under the Japanese definition of multiplication by measurement. It also explains that the reason why many countries in Central America, the Pacific, Southeast Asia, and so on choose Japanese textbooks is this consistent sequence to extend students' ideas for future learning.

Chapter 5 , in relation to the question of the definition and meaning of multiplication, illustrates how Japanese teachers introduce the meaning of multiplication under the definition of multiplication by measurement in two examples of lesson study. The capacity of the students to set the unit for measurement is enhanced in the Japanese classroom. Data on how Japanese students develop in the curriculum sequence are also provided. After these discussions, the Japanese and Chilean 
approaches for introducing the meaning of multiplication are compared. The way in which the Chilean curriculum explains how students make sense of multiplication is also shown. On the other hand, the Japanese engage in sense making for multiplication by enhancing the capacity of the students to set the unit for measurement.

Chapter 6, in relation to the question of the grade level at which the multiplication table should be taught, illustrates how the Japanese approach enables students to learn the skill to extend what they have learned and the significance of their learning. In Japan, the multiplication table is taught in the second grade, and this chapter explains three reasons for this. The first reason is the high achievement. The second reason is that students are able to extend the multiplication table by themselves in an appropriate teaching sequence. The third reason is that memorizing the table is an enjoyable activity for students as a cultural practice. In relation to the subtheme of this book, this chapter illustrates how students are able to extend the multiplication table by themselves in the task sequence.

Chapter 7, in relation to the question of multidigit multiplication, illustrates the extension of multiplication in vertical form and the column method, from single digit numbers to multidigit numbers, which includes the process of integration with addition in vertical form. Because multiplication of multidigit numbers by the column method is not repeated addition, students have to extend and integrate what they have already learned. In the Japanese approach, teachers prepare an appropriate task sequence that enables students to devise various approaches for vertical form and to choose the appropriate form in relation to the base ten place value system. Using the exemplar of lesson study and the teaching sequence in the textbook, three principles on how to design the task sequence using what the students have already learned are illustrated.

As explained in Section 1.1, to understand the Japanese approach to multiplication, readers have to note how the coherent alignment between the curriculum, textbooks, and teaching in Japan is planned through lesson study (see Isoda, Stephens, Ohara, and Miyakawa, 2007; Miyakawa and Winsløw, 2019). In Japan, the Ministry reforms the national curriculum every decade.$^{21}$ Textbooks, which condense teachers' experience of lesson study in relation to every subject, are revised every 4 years. ${ }^{22}$ Teachers must use the textbooks approved by the government, although they can create their own school curriculum. Teachers must also follow the national curriculum sequence. For countries in which every teacher teaches mathematics using their own independent curriculum, it may look like Japanese teachers are restricted by the national curriculum; however, this is a misunderstanding because the curriculum is the product of lesson study by teachers. ${ }^{23}$

In Japan, half of the university math educators are well-experienced schoolteachers. Most of these math educators work with teachers in the schools and are challenged

\footnotetext{
${ }^{21}$ This has been a gradual transformation of the system over several decades. For example, the subject of English has been introduced in three steps: in the first decade, it was recommended as an activity; in the second decade, English activity was done every week; and in the third decade, English became a subject to be learned.

${ }^{22}$ Textbooks are usually written by leading teachers of lesson study, and math educators usually contribute editing. Teachers in experimental schools usually collaborate with math educators for innovation of mathematics teaching.

${ }^{23}$ There are various misunderstanding for Japanese lesson study (see such as Isoda, 2015a; Fujii, 2014).
} 
to devise innovations in mathematics education. Members of curriculum reform committees are usually leading researchers and teachers in national-level lesson study. They are usually the authors of textbooks and members of national assessment committees. If they are engaged in lesson study, they try to embed their achievements in the national curriculum standards and textbooks that follow the national standards.

In this manner, lesson study has given way to harmonious progress between curriculum design and classroom management. It contributes to the aspiration of offering mathematics education centered on a problem-solving approach that is connected to the demands of addressing the content established in the curriculum, the teaching materials, and the task sequences, and developing students' interest/values and attitude in learning mathematics and mathematical thinking.

\subsection{Overview of Chapters in Part II, Focusing on Ibero-American Countries}

Part II of this English edition develops a proposal for teaching multiplication and offers reflections on it by leading researchers in Ibero-American countries, which provide diverse original views and deep critiques but are not necessarily representatives of the national approaches.

In Chap. 8, a contribution from Dr. Ubiratan D'Ambrosio and Dr. Claudia Sabba of Brazil is presented, which invites us to appreciate the development of their original ideas - an ethnomathematical perspective on the question of the idea of multiplication. The teaching approach is grounded on miniprojects that integrate diverse areas of knowledge in the Waldorf Schools tradition in Sao Paulo. There, the concept of multiplication is constructed together with the geometry of plane figures through the elaboration of mathematical thinking together with figures mounted on a circular wooden table. These ideas are connected to the use of photos taken using students' cellular phones to introduce the concept of proportionality. They take photos of their bodies and faces, and use them to study Leonardo da Vinci's Vitruvian Man.

Chapter 9 presents a contribution from Dr. David Block and Laura Resendiz of Mexico. They share a teaching sequence for addressing multiplication constructed and validated in the framework of French didactics engineering. The teaching proposal is made up of a sequence of didactic situations about a kind of proportionality relation in which each value of a set-the number of necklaces-is made to correspond, in another set, to pairs, threes, or $N \mathrm{~s}$ of values (numbers of beads of different colors required for that number of necklaces). The sequence includes multiplication, division, and proportionality problems. Also, the results of application of the sequence in a group of fourth-grade students (9-10 years of age) are presented.

The contribution in Chap. 10 comes from Professors Fatima Mendes, Jouana Brocardo, and Helia Oliveira of Portugal. The authors, bearing in mind the pedagogical notion of the "path," show how a teacher, as a sailor, adjusts the sails to correct the path and reach port, taking responsibility for third-grade students' learning regarding multiplication. The paths are associated with potential levels of achievement, learning goals, and competencies to be reached. So, while the study of learning tasks is connected to microdidactics and the study of teaching sequences is 
connected to mesodidactics, the study of hypothetical learning paths lies in the macrodidactic context particular to longitudinal study, which addresses the evolution of students' understanding of a concept over years.

Chapter 11 provides the last contribution, from Dr. Maria del Carmen Chamorro of Spain, who reflects on why so many children fail in learning multiplication in elementary schools in Ibero-American countries. She describes four problems: students' lack of understanding, lack of development of skill in written calculation, inappropriateness of common teaching methods, and the presence of the algorithm without controlling how it is produced. Dr. Chamorro points out the virtues of Japanese teaching with respect to the importance of meaning or semantic dimension, the importance given in Japan to the use of manipulatives, and the relevance of the cultural dimension.

\section{References}

Baba, T., Ueda, A., Ninomiya, H., \& Hino, K. (2018). Mathematics education lesson study in Japan from historical, community, institutional and development assistance perspectives. In M. Quaresma, C. Winslow, S. Clivaz, J. P. Pnde (Eds.), Mathematics Lesson Study Around the World (pp. 23-25). New York, NY: Springer.

Becker, J., \& Shimada, S. (1997). The open-ended approach: A new proposal for teaching mathematics. Reston, VA: National Council of Teachers of Mathematics. (Original Japanese book published in 1977 from Misuumishobo).

Chevallard, Y. (2015). Teaching mathematics in tomorrow's society: A case for an oncoming counter paradigm. In S. J. Cho (Ed.), Proceedings of the 12th International Congress on Mathematical Education (pp. 173-187). Cham, Switzerland: Springer.

Clements, D., \& Sarama, J. (2004). Learning trajectories in mathematics education. Mathematical Thinking and Learning, 6, 81-89. https://doi.org/10.1207/s15327833mt106021

Emori, H. (2013). Two types of reflective thinking on the emergent chain of mathematical communication. Inprashitha, M,, et al edited. 6th East Asia Regional Conference on Mathematics Education Innovations and Exemplary Practices in Mathematics Education, 1, pp.99-123.

Freudenthal, H. (1973). Mathematics as an educational task. Dordrecht, The Netherlands: Reidel.

Fujii, T. (2014). Implementing Japanese lesson study in foreign countries: Misconceptions revealed. Mathematics Teacher Education and Development, 16(1). 1-17.

Herbst, P., Chazan, D. (2016). The Role of Theory Development in Increasing the Subject Specificity of Research on Mathematics Teaching. Reston, VA, USA: National Council of Teachers of Mathematics

Hiebert, J. (Ed.). (1986). Conceptual and procedural knowledge: The case of mathematics. Hillsdale, NJ: Lawrence Erlbaum.

Huang, R. \& Shimizu, Y. (2016). Improving teaching, developing teachers and teacher educators, and linking theory and practice through lesson study in mathematics: an international perspective. ZDM, 48, 393-409.

Isoda, M. (1992). Designing problem solving approach with cognitive conflict and appreciation. Iwamizawa, Japan: Hokkaido University of Education (written in Japanese.

Isoda, M. (1996). Problem solving approach beyond cognitive conflicts based on conceptual and procedural knowledge at primary school. Tokyo, Japan: Meijitosho. (Written in Japanese).

Isoda, M. (2007). History of lesson study. In M. Isoda, M. Stephens, Y. Ohara, \& T. Miyakawa (Eds.), Japanese lesson study in mathematics. Singapore, Singapore: World Scientific.

Isoda, M. (2009). Theory of conceptual and procedural knowledge into Japanese problem solving approach. In C. Litwin, edited. (Ed.), Proceedings of the Conference on Mathematics Teaching and Assessment. Hong Kong, China: Hong Kong Institute of Education. 
Isoda, M. (2012). Introductory chapter: Problem solving approach to develop mathematical thinking. In M. Isoda \& S. Katagiri (Eds.), Mathematical thinking: How to develop it in the classroom (pp. 1-28). Hackensack, NJ: World Scientific.

Isoda, M. (2015a). The science of lesson study in the problem solving approach. In M. Inprasitha, M. Isoda, P. Wang-Iverson, \& B. Yap (Eds.), Lesson study: Challenges of mathematics education (pp. 81-108). Singapore, Singapore: World Scientific.

Isoda, M. (2015b). Dialectic on the problem solving approach: Illustrating hermeneutics as the ground theory for lesson study in mathematics education. In S. J. Cho (Ed.), Selected regular lectures from the 12th International Congress on Mathematical Education (pp. 355-381).

Isoda, M. (2018). Mathematization: A theory for curriculum desing. In Kawazoe, M. edited. Proceedings of the International Workshop on Mathematics Education for Non-Mathematics Students Developing Advanced Mathematical Literacy. pp.27-34. Retrieved from: http://iwme. jp/pdf/Proceedings_IWME2018.pdf

Isoda, M. (2020). Producing theories for mathematics education through collaboration: A historical development of Japanese lesson study. In H, Borko, D. Potari (eds.), Proceedings of 25 ICMI Studies: Teachers of Mathematics Working and Learning in Collaborative Groups (pp. 15-22). Lisbon: University of Lisbon.

Isoda, M., \& Katagiri, S. (2012). Mathematical thinking: How to develop it in the classroom. Singapore, Singapore: World Scientific.

Isoda, M., \& Katagiri, S. (2016). Pensamiento matemtico: Como desarrollarlo en la sala de clases. (Co. by Roberto Araya) CIAE, Universidad de Chile, Santiago, Chile.

Isoda, M., \& Olfos, R. (2009a). El estudio de clases y los requerimientos curriculares: El caso de la multiplicación [in English: Teaching of multiplication: Lesson study for curricular demands]. Valparaíso, Chile: Ediciones Universitarias de Valparaíso.

Isoda, M., \& Olfos, R. (2009b). El enfoque de resolución de problemas en la enseñanza de la matemática a partir del estudio de clases (Problem solving approach: Mathematics teaching on lesson study). Valparaíso, Chile: Ediciones Universitarias de Valparaíso.

Isoda, M., \& Olfos, R. (Eds.). (2011). Enseñanza de la multiplicación: Desde el estudio de clases Japonés a las propuestas Iberoamericanas (Teaching multiplication: Japanese lesson study and Ibero-American contributions). Valparaíso, Chile: Ediciones Universitarias de Valparaíso.

Isoda, M., Stephens, M., Ohara, Y., \& Miyakawa, T. (Eds.). (2007). Japanese lesson study in mathematics: Its impact, diversity and potential for educational improvement. Singapore, Singapore: World Scientific.

Ito, T. (1961). Critique to water supply system (method). Journal of Saitama University Science of Education, 10, 17-63. (Written in Japanese).

Ito, T. (1962a). Some criticisms about the water supply system: For separatism on concept and operation of number. Journal of the Mathematical Educational Society of Japan, 44(8), 114 118. (Written in Japanese).

Ito, T. (1962b). Some criticisms about the water supply system (2): Separatism on concept and operation of number. Journal of the Mathematical Educational Society of Japan, 44(10), 132 136. (Written in Japanese).

Ito, T. (1962c). Some criticisms about the water supply system method: For the principal of water supply system method (1). Journal of the Mathematical Educational Society of Japan, 44(12), 168-172. (Written in Japanese).

Ito, T. (1963a). Some criticisms about the water supply system (4): For the principal of the water supply system (2). Journal of the Mathematical Educational Society of Japan, 45(2), 10-15. (Written in Japanese).

Ito, T. (1963b). Some criticisms about the water supply system (3). Journal of the Mathematical Educational Society of Japan, 45(4), 63-68. (Written in Japanese).

Ito, T. (1963c). Some criticisms about the water supply system: The principal and precedence on algorism. Journal of the Mathematical Educational Society of Japan, 45(6), 106-111. (Written in Japanese).

Ito, T. (1968). Modernization of teaching problem solving. Tokyo, Japan: Meijitosho. (Written in Japanese).

Ito, T. (1971). The theory and methods on discovery teaching. Journal of Saitama University, Science of Education, 20, 75-88. 
Izak, A., \& Beckmann, S. (2019). Developing a coherent approach to multiplication and measurement. Educational Studies in Mathematics, 101, 83-103.

Katagiri, S., Sakurai, T., \& Takahasi, E. (1969). Mathematical thinking and its teaching. Journal of the Research Institute of Education for Capital Tokyo, 1, 83-155.

Katagiri, S., Sakurai, T., Takahasi, E., \& Oshima, T. (1971). Mathematical thinking and its teaching at primary school. Tokyo, Japan: Kindasishinsyo.

Kobayasi, M. (1989). New ideas of teaching mathematics in Japan. Tokyo, Japan: Tyuou Daigaku Publisher.

Lakatos, I. (1976). Proofs and refutations. Cambridge: Cambridge University Press.

Lerman, S. edited (2014). Encyclopedia of Mathematics Education. Cham, Switzerland: Springer

Makinae, N. (2010). The origin of lesson study in Japan. Proceedings of the 5th East Asia Regional Conference on Mathematics Education, Vol 2, 140-147.

Makinae, N. (2016). The development of mathematics education as seen in mathematics education controversies in Japan. History and Pedagogy of Mathematics. hal-01349246.

Mangao, D., Ahmad, J., \& Isoda, M. (2017). SEAMEO Basic Education Standards (SEA-BES): Common Core Regional Learning Standards (CCRLS) in mathematics and science. Penang, Malaysia: SEAMEO RECSAM.

McCallum, W. (2018). Making sense of mathematics and making mathematics make sense. In Proceedings of ICMI Study 24 School Mathematics Curriculum Reforms: Challenges, changes and opportunities (pp. 1-8). Tsukuba, Japan: University of Tsukuba.

Ministry of Education. (1947). Course of study for school mathematics (recommendation). Tokyo, Japan: Ministry of Education.

Ministry of Education. (1956). Course of study for high school mathematics. Tokyo, Japan: Ministry of Education.

Ministry of Education. (1998). Course of study for elementary school. Tokyo, Japan: Ministry of Education. Retrieved from: http://www.mext.go.jp/a_menu/shotou/cs/1319944.htm

Miyakawa, T., \& Winsløw, C. (2013). Developing mathematics teacher knowledge: The paradidactic infrastructure of "open lesson" in Japan. Journal Mathematics Teacher Education, 16, 185-209.

Miyakawa, T., \& Winsløw, T. (2019). Paradidactic infrastructure for sharing and documenting mathematics teacher knowledge: A case study of "practice research" in Japan. Journal Mathematics Teacher Education, 22, 281-303.

Murata, A. (2008). Mathematics teaching and learning as a mediating process: The case of tape diagrams. Mathematical Thinking and Learning, 10, 374-406.

NCMS. (2000). Before It's Too Late: A Report to the Nation from the National Commission on Mathematics and Science Teaching for the 21st Century. Washington, DC: NCSM.

NCTM [National Council of Teachers of Mathematics]. (1980). An agenda for action: Recommendations for school mathematics of the 1980s. Reston, VA: NCTM.

Nohda, N. (1983). Open approach in mathematics education. Tokyo, Japan: Toyokan.

Nohda, N. (2000). Teaching by open-approach method in Japanese mathematics classroom. In T. Nakahara \& M. Koyama (Eds.), Proceeding of the 24th Conference of the International Group for the Psychology of Mathematics Education (PME 24) (pp. 39-54). Hiroshima, Japan: Hiroshima University.

OECD [Organisation for Economic Co-operation and Development]. (2005). The definition and selection of key competency. Paris, France: OECD. Retrieved from: https://www.oecd.org/ pisa/35070367.pdf

Odaka, T., \& School Mathematics Study Society at the Junior Secondary School of the Tokyo University of Education. (1969). Experimental study of new mathematics: Planning. Tokyo, Japan: Kindaishinsyo.

Odaka, T., \& School Mathematics Study Society at the Junior Secondary School of the Tokyo University of Education. (1970). Experimental study of new mathematics: Grade 1. Tokyo, Japan: Kindaishinsyo.

Odaka, T., \& School Mathematics Study Society at the Junior Secondary School of the Tokyo University of Education. (1971). Experimental study of new mathematics: Grade 2. Tokyo, Japan: Kindaishinsyo.

Odaka, T., \& School Mathematics Study Society at the Junior Secondary School of the Tokyo University of Education. (1972). Experimental study of new mathematics: Grade 3. Tokyo, Japan: Kindaishinsyo. 
Odaka, T. (1975). Principle of mathematics teaching. Tokyo, Japan: Tokyokan.

Odaka, T. (1979). Development of schema for elementary school mathematics: Mapping of basic concept for learning. Tokyo, Japan: Tokyokan.

Odaka, T. (1980). Development of schema for junior secondary school mathematics: Mapping of basic concept for learning. Tokyo, Japan: Tokyokan.

Odaka, T., \& Okamoto, K. (1982). Task sequence for junior secondary school mathematics lessons: Exemplar approach based on schema theory. Tokyo, Japan: Tokyokan.

Pólya, G. (1945). How to solve it. Princeton, NJ: Princeton University Press.

Rasmussen, K., \& Isoda, M. (2018). The intangible task: A revelatory case of teaching mathematical thinking in Japanese elementary schools. Research in Mathematics Education, 21(1), 43-59. https://doi.org/10.1080/14794802.2018.1555714

Robutti, O., et al. (2016). ICME international survey on teachers working and learning through collaboration. ZDM, 48, 651-690.

Sakai, K., \& Hasegawa, K. (1989). Designing mathematics lesson by dialectic and inquiry approach. Tokyo, Japan: Kyouikusyuppan.

Sfard, A. (1991). On the dual nature of mathematical conceptions: Reflections on processes and objects as different sides of the same coin. Educational Studies in Mathematics, 22, 1-36.

Shimizu, S. (1984). Designing mathematics education for students who learn mathematics by and for themselves. Epsilon: Mathematics Education Journal of the Aichi University of Education, $26,92-114$.

Simon, M. A. (1995). Reconstracting Mathematics Pedagogy from a Constractivist Perspective, Journal for Research in Mathematics Education.

Squires, D. (2012). Curriculum alignment research suggests that alignment can improve students achievement. The Clearing House, 85, 129-135.

Stigler, J. W., \& Hiebert, J. (1999). The teaching gap: Best ideas from the world's teachers for improving education in the classroom. New York: Free Press.

Tall, D. (2013). How humans learn to think mathematically: Exploring the three worlds of mathematics. New York: Cambridge University Press.

United Nations. (2015). Sustainable development goals. New York: United Nations. Retrieved from: https://www.un.org/sustainabledevelopment/sustainable-development-goals/.

Vygotski, L. S. (1978). Mind in society: The development of higher psychological processes. Cambridge, MA: Harvard University Press.

Wakabayashi, T., \& Shirai, T. (Eds.). (1883). Revision of teaching (in Japanese: Kaisei Kyoujyu Jyutu). Tokyo, Japan: Fukyusya.

Winsløw, C., Matheron, Y., \& Mercier, A. (2013). Study and research courses as an epistemological model for didactics. Educational Studies in Mathematics, 83(2), 267-284.

Open Access This chapter is licensed under the terms of the Creative Commons Attribution 4.0 International License (http://creativecommons.org/licenses/by/4.0/), which permits use, sharing, adaptation, distribution and reproduction in any medium or format, as long as you give appropriate credit to the original author(s) and the source, provide a link to the Creative Commons licence and indicate if changes were made.

The images or other third party material in this chapter are included in the chapter's Creative Commons licence, unless indicated otherwise in a credit line to the material. If material is not included in the chapter's Creative Commons licence and your intended use is not permitted by statutory regulation or exceeds the permitted use, you will need to obtain permission directly from the copyright holder. 